\title{
RESPOSTA DA SOJ A À ADUBAÇÃO POTÁSSICA EM LATOSSOLO HÚMICO DISTRÓFICO NUM PERÍODO DE DOZE ANOS ${ }^{(1)}$
}

\author{
E. E. SCHERER(2)
}

\begin{abstract}
RESUMO
A capacidade de suprimento de potássio do solo, a resposta da soja à adubação potássica e o efeito residual do adubo foram determinados em um experimento no campo, conduzido, por doze anos consecutivos, em um Latossolo Húmico de Santa Catarina. Os tratamentos constaram de quatro doses de $\mathrm{K}_{2} \mathrm{O}\left(0,80,160\right.$ e $\left.320 \mathrm{~kg} \mathrm{ha}^{-1}\right)$, distribuídas a lanço e incorporadas ao solo, nas parcelas, somente no primeiro ano de cultivo; três doses de $\mathrm{K}_{2} \mathrm{O}\left(0,40\right.$ e $\left.80 \mathrm{~kg} \mathrm{ha}^{-1}\right)$, aplicadas a lanço, anualmente, nas subparcelas, a partir do quinto ano de cultivo, e um tratamento adicional, com aplicação anual de $40 \mathrm{~kg} \mathrm{ha}^{-1}$ de $\mathrm{K}_{2} \mathrm{O}$, no sulco. Avaliações de $\mathrm{K}$ no solo e de rendimento de grãos foram feitas anualmente. Nos primeiros quatro anos, não houve resposta da cultura à aplicação de $\mathrm{K}$. A partir do quinto ano, as respostas à adubação potássica anual foram crescentes. Na média das doze colheitas, cada qui lograma de $\mathrm{K}_{2} \mathrm{O}$, aplicado ao solo no primeiro ano, resultou num acréscimo médio de $18 \mathrm{~kg} \mathrm{ha}^{-1}$ de grãos de soja. Uma aplicação anual de $60 \mathrm{~kg} \mathrm{ha}^{-1} \mathrm{de} \mathrm{K}_{2} \mathrm{O}$ foi suficiente para manter a produtividade da cultura acima de $90 \%$ da produção máxima.
\end{abstract}

Termos de indexação: Glycine max (L.) Merrill, produção de grãos, potássio, disponibilidade, efeito residual.

\section{SUMMARY: SOYBEAN RESPONSE TO POTASSIUM FERTILIZER ON A HAPLOHUMOX SOIL OVER A 12-YEAR PERIOD}

Supplying capacity, response to fertilization and residual effect of $K$ fertilization were evaluated in a twelveyear soybean field experiment on a Haplohumox soil, in Campos Novos, State of Santa Catarina, Brazil. Treatments consisted of: four levels of $\mathrm{K}_{2} \mathrm{O}(0,80,160$ and $\left.320 \mathrm{~kg} \mathrm{ha}^{-1}\right)$, applied only in the first cropping, on the whole plots; thre levels of $\mathrm{K}_{2} \mathrm{O}(0,40$ and $80 \mathrm{~kg} \mathrm{ha}^{-1}$ ), applied annually in the sub-plots from the fifth year; one treatment with application of $40 \mathrm{~kg} \mathrm{ha}^{-1}$ of $\mathrm{K}_{2} \mathrm{O}$ in the furrow. All treatments were applied in a split plot arrangement in RCB design with threereplications. Soil analysis and grain yield weremeasured every year. Therewas no response on soybean yield to $K$ fertilization during the first four years. Beginning the fifth year, all treatments had higher yields than the control. Yield response to

\footnotetext{
(1) Recebido para publicação em fevereiro de 1997 e aprovado em novembro de 1997.

(2) Pesquisador da EPAGRI-Centro de Pesquisa para Pequenas Propriedades (CPPP). Caixa Postal 791, CEP 89801-970 Chapecó (SC).
} 
annual fertilization increased with timeand with decreasing residual $\mathrm{K}$ rates in the soil. On the average of 12-year period, the grain yield increased $18 \mathrm{~kg}$ per $\mathrm{kg}$ of $\mathrm{K}_{2} \mathrm{O}$ applied at the first cropping. A fertilization of $60 \mathrm{~kg} \mathrm{ha}^{-1} \mathrm{~K}_{2} \mathrm{O}$ year-1 may maintain soybean yield at about $90 \%$ of maximum productivity over a 12 year period.

Index terms: Glycine max (L.) Merrill, grain yiedd, potassium, availability and resi dual effect.

\section{INTRODUÇÃO}

O cultivo desoja noEstado deSanta Catarina está concentrado na região Oeste, em áreas favoráveis à mecanização, na sua maioria, Latossolos. E sses solos, em seu estado natural, caracterizam-se pela el evada acidez e baixa disponibilidade de P. Por essa razão, deu-se, inicialmente, maior ênfase ao estudo desses dois fatores, ficando os relativos à adubação potássica em segundo plano, mesmo sabendo ser o potássio um dos nutrientes exportados em maiores quantidades pela cultura da soja.

Atualmente, em virtude da utilização continuada de formulações comerciais com altos teores de $\mathrm{P}$ e baixos teores de K na adubação da soja, há um esgotamento gradativo dos sol os euma tendência cada vez maior ao aparecimento de áreas com baixos teores deK no solo. Assim, prevê-se a crescente importância da adubação potássica na agricultura catarinense, à semelhança do que já acontece em outros Estados (Mielniczuk, 1982; Mascarenhas et al., 1987; 1988; Borkert et al., 1993).

Em geral, nos estudos com adubação potássica em soja, têm predominado ensaios de curta duração, na maioria dos casos, não ultrapassando três anos de avaliação no mesmo local (Ben, 1981; Muzilli, 1982). Nessas condições, grande parte dos Latossolos de origem basáltica da região Sul do País têm uma reserva de K suficiente para atender às necessidades das culturas, sem acarretar quedas de rendimento nos primeiros anos de sua exploração (Voll \& Bays, 1976; Siqueira, 1982; Scherer et al., 1982).

Ensaios de campo indicam que o $\mathrm{K}$ do adubo pode apresentar efeito residual prolongado no solo, principal mente quando doses el evadas são aplicadas em sol os deficientes desse nutriente. Porém, no Brasil, ao contrário de outros países, praticamente não se dispõe de informações de resultados de pesquisa com adubação potássica de longa duração em culturas anuais (Muzilli, 1982). Muitos experimentos com avaliação do efeito residual foram desenvolvidos em casa de vegetação (Mielniczuk \& Selbach, 1978; Rosolem et al., 1988; Nachtigall \& Vahl, 1991; Fernandes et al., 1993), e raros foram os ensaios realizados no campo, por um período superior a três anos, no mesmo local (Borkert et al., 1993). Para melhor conhecimento da dinâmica do K no solo, da capacidade do solo no suprimento do nutriente às plantas e do efeito da adubação potássica ao longo do tempo, torna-se fundamental a realização de maior número de experimentos de campo de longa duração.
Somente assim, será possível obter resultados mais reais na quantificação da adubação potássica a ser aplicada em determinadas situações de solo e de sistemas de cultivo, como destacaram Mielniczuk (1982) e Siqueira (1982).

Estetrabal ho teve por objetivo aval iar a capaci dade de suprimento de $\mathrm{K}$ do solo e determinar a resposta da soja à adubação potássica, bem como quantificar seu efeito residual no solo.

\section{MATERIAL E MÉTODOS}

O experimento foi realizado, por doze anos consecutivos, com a cultura da soja, no município de Campos Novos, Santa Catarina, em sol o argi loso (69\% de argila), classificado como Latossolo Húmico distrófico. Antes da implantação do experimento, a área estava com campo nativo, com as seguintes caraterísticas químicas na camada arável $(0-20 \mathrm{~cm})$ : pH 4,7 (água 1:1); $1,6 \mathrm{mg} \mathrm{dm}^{-3}$ de P-disponível (Mehlich-1); $125 \mathrm{mg} \mathrm{dm}^{-3}$ de K-disponível (Mehlich-1); 2,4 $\mathrm{cmol}_{\mathrm{C}} \mathrm{dm}^{-3}$ de Ca + Mg-trocáveis (KCl $1 \mathrm{~mol} \mathrm{~L}^{-1}$ ); $2,4 \mathrm{cmol}_{\mathrm{c}} \mathrm{dm}^{-3}$ de Al trocável; $81 \mathrm{~g} \mathrm{~kg}^{-1}$ de matéria orgânica (combustão úmida).

Foram aplicadas 8,9 t ha-1 de cal cário dolomítico, visando elevar o pH da camada arável a, aproximadamente, 6,0. A baixa disponibilidade de $\mathrm{P}$ do solo foi corrigida com a aplicação de 160 kg ha-1 de $\mathrm{P}_{2} \mathrm{O}_{5}$ na forma de superfosfato triplo.

O delineamento experimental utilizado foi o de blocos casualizados, com parcelas divididas, com três repetições. No primeiro ano, foram aplicadas quatro doses de adubo: 0, 80, 160 e $320 \mathrm{~kg}^{2} \mathrm{ha}^{-1}$ de $\mathrm{K}_{2} \mathrm{O}$ nas parcelas principais. No quinto ano, após constatar respostas à adubação potássica, as parcelas foram divididas em quatro subparcelas, constituídas de uma testemunha (sem adubo potássico) e três com adubo potássico (40 e $80 \mathrm{~kg} \mathrm{ha}^{-1}$ de $\mathrm{K}_{2} \mathrm{O}$, aplicados a lanço, e $40 \mathrm{~kg} \mathrm{ha}^{-1}$ de $\mathrm{K}_{2} \mathrm{O}$, aplicados no sulco). $\mathrm{O}$ adubo potássico $(\mathrm{KCl})$ das subparcelas foi aplicado, anualmente, na semeadura da cultura principal (soja), juntamente com uma adubação básica de $P$, suprida de acordo com a análise do solo.

As parcelas foram constituídas por seis linhas de soja, espaçadas de $0,6 \mathrm{~m}$, com comprimento de $23,0 \mathrm{~m}$, as quais foram divididas em quatro subparcelas de 5,0 m de comprimento, mantendo um espaço de $1,0 \mathrm{~m}$ entre elas. O mesmo espaço foi mantido entre as parcelas, visando aumentar a bordadura e reduzir a 
contaminação entre tratamentos durante o preparo do sol o. A soja, cultivar Bragg, foi semeada em sistema de rotação com culturas de inverno, em que o trigo foi a única cultura comercial, semeada a cada 3 anos, conforme a seguinte seqüência de cultivos: (1) soja/ trigo; (2) soja/pousio; (3) soja/pousio; (4) soja/trigo; (5) soja/pousio; (6) soja/pousio; (7) soja/trigo; (8) soja/ azevém; (9) soja/aveia; (10) soja/trigo; (11) soja/xinxo; (12) soja/pousio.

Antes da implantação da soja, o solo foi revolvido com grade de discos ou enxada rotativa, fazendo-se, manual mente, a semeadura e deixando-se 24 plantas por metro de sulco. A cultura da soja, com as sementes devidamente inoculadas com Bradyrhizobium japonicum, foi implantada em final de novembro ou início de dezembro e, normalmente, col hida em abril ou maio; as culturas de inverno em junho/julho, e col hidas (trigo) ou incorporadas ao sol o em novembro.

Para obter o rendimento de grãos, foram col hidas quatrolinhas centrais de cada subparcela, perfazendo uma área útil de 9,6 m². Não houve reposição da palhada das culturas comerciais (soja e trigo) nas parcelas, após a trilha. No caso das culturas protetoras do solo, houvea incorporação dos resíduos por ocasião da semeadura da soja.

Após cada col heita da soja, foi feita a amostragem do solo na camada de $0-20 \mathrm{~cm}$, retirando-se 20 subamostras em cada subparcela, para análise do teor de $\mathrm{K}$ e monitoramento da sua fertilidade, segundo método da Comissão de Fertilidade do Solo (1995). Real izaram-se anál ises estatísticas da variância e de regressão, adotando-se $5 \%$ como nível de significância. $\mathrm{O}$ rendimento relativo foi calculado, dividindo-se o rendimento de grãos obtido em cada tratamento pela produtividade máxima do experimento no respectivo ano e multiplicando-se por 100.

\section{RESULTADOS E DISCUSSÃO}

\section{Rendimento de grãos}

A produtividade média do experimento, duranteo período, variou de 1.335 a $3.408 \mathrm{~kg} \mathrm{ha}-1$, e a produtividade máxima, de 1.771 a $3.482 \mathrm{~kg} \mathrm{ha-1,} \mathrm{com}$ um valor médio de $2.500 \mathrm{~kg} \mathrm{ha}^{-1}$ de soja. I sso indica que, em nenhum ano, houve limitação drástica da produtividade, causada por outros fatores, além da deficiência de potássio. Os curtos períodos de estiagem não chegaram a comprometer o rendimento de grãos.

A figura 1 mostra os rendimentos de grãos, al cançados nas doze col heitas de soja com a aplicação de doses crescentes de adubo potássico somente no primeiro cultivo.

Do primeiro ao quarto cultivo de soja, não houve diferença significativa entre os tratamentos (com e sem adubo potássico). A falta de resposta da cultura à adubação potássica nos quatro primeiros anos pode ser atribuída aoal toteor deK-disponível peloMehlich-1, no solo, quando da instalação do experimento

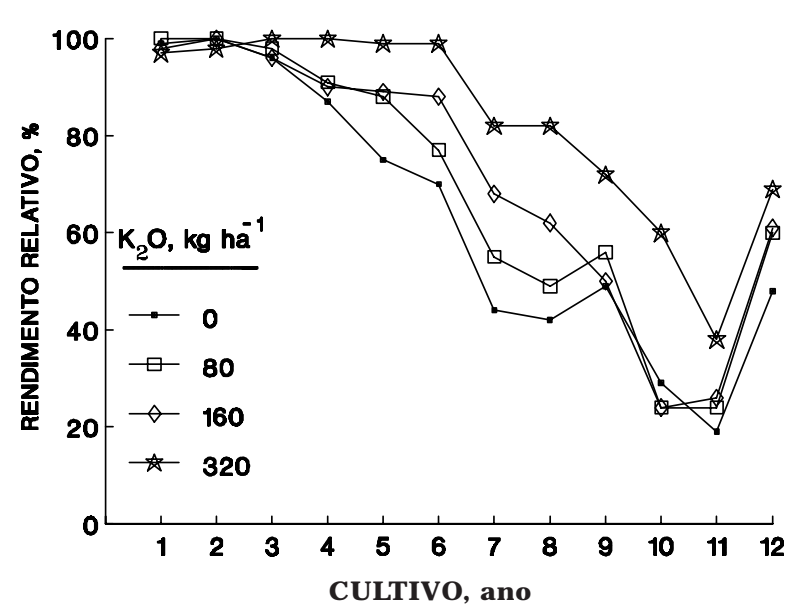

Figura 1. E feito residual da adubação potássica no rendimento relativo de soja ao longo de doze anos de cultivo. Média de três repetições.

(125 mg dm-3), superior ao nível crítico de $80 \mathrm{mg} \mathrm{dm}^{-3}$ para esse sol o (Comissão de Fertilidade do Solo RS/SC, 1995). Fato semel hante foi observado por Voll \& Bays (1976), em um experimento conduzido por três anos, em Latossolo Roxo do Oeste Catarinense, e por Ben (1981) e Siqueira (1982), em solos recém-cultivados do Planal to Riograndense. Esses autores mostraram que, normalmente, as reservas de $\mathrm{K}$ dos Latossolos argi losos são suficientes para atender às necessidades das culturas nos primeiros cultivos.

Assim sendo, respostas significativas da soja à adubação potássica só foram observadas no quinto ano, quando o teor de $\mathrm{K}$ do solo na testemunha decresceu para $57 \mathrm{mg} \mathrm{dm}^{-3}$. A análise de regressão evidenciou uma resposta linear da cultura para as doses de $\mathrm{K}$ aplicadas no primeiro ano.

A partir do sexto ano, verificou-se maior resposta da soja à adubação potássica, com nítida diferenciação no rendimento de grãos entre os tratamentos com níveis residuais de adubo potássico, bem como entre estes ea testemunha. Essa diferenciação persistiu até o oitavo ano, quando o rendimento de grãos, nos tratamentos de efeito residual de 80 e $160 \mathrm{~kg} \mathrm{ha}^{-1}$ de $\mathrm{K}_{2} \mathrm{O}$, foi semel hante ao da testemunha, indicando que a maior parte do $\mathrm{K}$ adicionado no primeiro ano foi consumido pelas sucessivas col heitas. Somente o tratamento com $320 \mathrm{~kg} \mathrm{ha}^{-1}$ de $\mathrm{K}_{2} \mathrm{O}$ apresentou marcante efeito residual sobre a produção de soja ao longo dos demais anos.

Nos primeiros seis anos, apesar da resposta à adubação potássica, não foram encontrados sintomas visuais de deficiência, caracterizando a "fome oculta". A partir do sétimo ano, os sintomas foliares de deficiência se evidenciaram de forma característica em todas as parcel as não adubadas com potássio. Nos anos subseqüentes, também as parcelas que receberam 80, 160 e $320 \mathrm{~kg} \mathrm{ha}^{-1}$ de $\mathrm{K}_{2} \mathrm{O}$ no primeiro cultivo, mas sem adubação anual, apresentaram plantas com sintomas visuais de deficiência deK. Com 
o passar dos anos e, à medida que a deficiência foi aumentando, as plantas apresentaram outros sintomas característicos, como maior suscetibilidade ao ataque de pragas, haste verde, morte da gema apical, maturação desuniforme, retenção foliar e aumento do número de vagens verdes por ocasião da sua maturação fisiológica, concordando com os sintomas descritos por diversos autores (Mascarenhas et al., 1987; Mascarenhas et al., 1988; Raij, 1991; Borkert et al., 1993).

Noúltimo ano $\left(12^{\circ}\right.$ cultivo desoja), verificou-se um aumento generalizado no rendimento de grãos em todos os tratamentos, até na testemunha. Tal aumento deve ser atribuído à associação de dois fatores: cultura anterior e clima. Os benefícios causados pela incorporação da massa verde da cultura do xinxo (Latyrus sativus), cultivado nos meses de inverno para cobertura do solo, e pelas condições climáticas bastante favoráveis para a cultura da soja, proporcionaram melhor aproveitamento do K do solo. A incorporação da massa do xinxo permitiu a reciclagem entre 8 e 15 kg ha-1 de $\mathrm{K}_{2} \mathrm{O}$, nas parcelas sem adubação anual, e entre 17 e 48 kg ha-1, nas parcelas que receberam $\mathrm{K}$, anualmente.

Na figura 2, apresenta-se o rendimento acumulado de grãos de soja, obti do nos tratamentos com adubação potássica anual.

Analisando os dados, verifica-seque os tratamentos que receberam aplicação anual de $80 \mathrm{~kg} \mathrm{ha-1}$ de $\mathrm{K}_{2} \mathrm{O}$ foram os melhores em todos os cultivos, somente diferindo estatisticamente dos tratamentos com aplicação anual de $40 \mathrm{~kg} \mathrm{ha}^{-1}$ de $_{2} \mathrm{O}$ nas parcelas com aplicação inicial de 0 e 80 kg ha-1 deK 20 (Figura 2a,b) e, neste último, somente nos dois últimos anos. Isso indica que a aplicação de $160 \mathrm{~kg} \mathrm{ha}-1$ de $\mathrm{K}_{2} \mathrm{O}$ no primeiro ano, complementada com uma aplicação anual de 40 kg ha-1 de $\mathrm{K}_{2} \mathrm{O}$ a partir do quinto ano, num total de $480 \mathrm{~kg}$ de $\mathrm{K}_{2} \mathrm{O}$ em doze anos, foi suficiente para manter a produtividade da soja no nível elevado ao longo desse período. Como nos primeiros quatro anos não houve resposta à adubação potássica, a quantidade de $\mathrm{K}_{2} \mathrm{O}$ aplicada no primeiro cultivo (160 kg ha-1) deve ser somada às quantidades aplicadas anual mentee dividida pel o número de anos com resposta à adubação potássica. Dessa forma, a quantidade média de adubo potássico a ser aplicada, anualmente, na soja, passa a ser de $60 \mathrm{~kg} \mathrm{ha-1} \mathrm{de} \mathrm{K}_{2} \mathrm{O}$. Essa quantidade de adubo é suficiente para al cançar uma produtividade média de grãos de 3 t ha-1, tomando como base uma retirada média de $21,5 \mathrm{~kg}$ de $\mathrm{K}_{2} \mathrm{O}$ para cada tonelada de grãos colhida (Mascarenhas et al., 1980).

A longo prazo, não houve diferenças no aproveitamento da adubação potássi ca apl icada numa única vez, somente no primeiro ano, ou de forma parcelada, com aplicações anuais, a partir do quinto ano. Isso pode ser comprovado pela comparação das médias de produtividade do tratamento com uma aplicação inicial de $\mathrm{K}_{2} \mathrm{O}$ maior ( $320 \mathrm{~kg} \mathrm{ha}-1$ ) e uma adubação anual menor (40 kg ha-1) (Figura 2d) com o tratamento que não recebeu potássio no primeiro ano, mas com uma adubação anual maior (80 kg ha-1 de $\mathrm{K}_{2} \mathrm{O}$ ) (Figura 2a), totalizando, ao final dos doze anos, 640 kg ha-1 de $\mathrm{K}_{2} \mathrm{O}$, em ambos os tratamentos, e uma produção acumulada de, aproximadamente, $30 \mathrm{t}$ de grãos em doze safras. Não houve diferença de rendimento de grãos causada pela forma de distribuição do adubo (40 kg ha-1 de $\mathrm{K}_{2} \mathrm{O}$ ) a lanço ou no sulco (Figura 3), tampouco foram observados sintomas de fitotoxicidade por cl oro ou concentração excessiva de sais na aplicação localizada do adubo. Segundo Mascarenhas et al. (1988), a aplicação localizada de altas doses de $\mathrm{KCl}$ pode prejudicar o desenvolvimento inicial das plantas de soja, principalmente em períodos de estiagem.

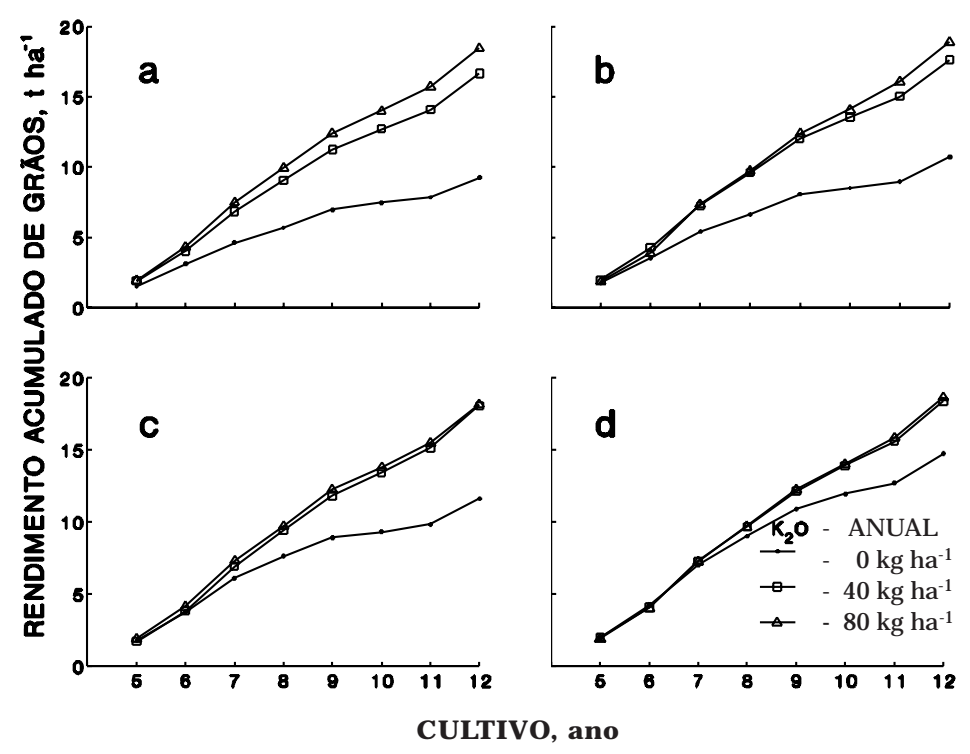

Figura 2. Rendimento acumulado de grãos de soja, em resposta às doses de adubo potássi co $(0,40$ e 80 kg ha-1 de $\mathrm{K}_{2} \mathrm{O}$ ), aplicadas, anualmente, a partir do quinto ano, nas diferentes doses de adubação potássica do primeiro ano (a: 0, b: 80, c: 160 e d: $320 \mathrm{~kg} \mathrm{ha}^{-1}$ de $\mathrm{K}_{2} \mathrm{O}$ ). Média de três repetições. 


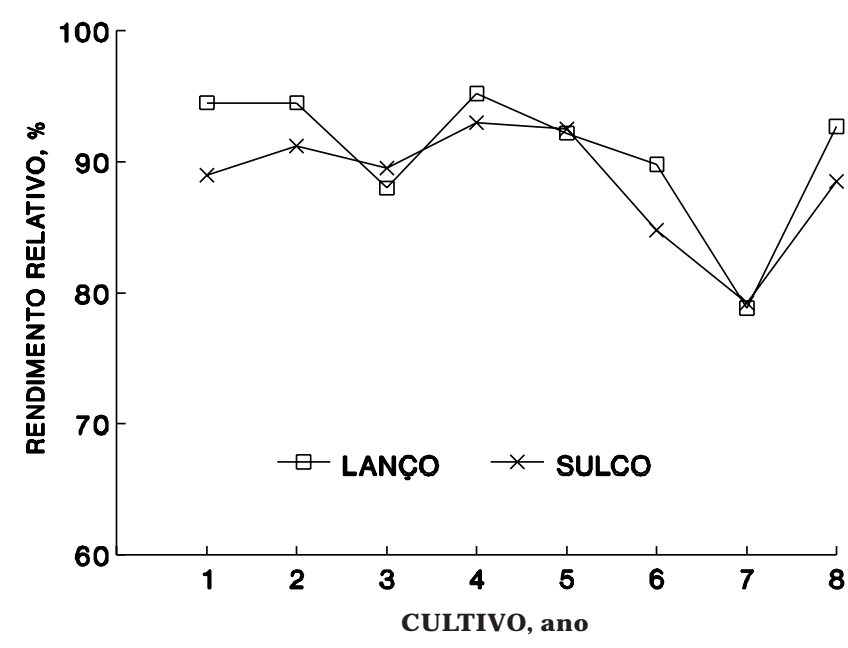

Figura 3. Rendimento de grãos de soja em função da aplicação anual de $40 \mathrm{~kg} \mathrm{ha}^{-1}$ de $\mathrm{K}_{2} \mathrm{O}$ no sulco de semeadura ou a lanço. Média de três repetições.

A produção de grãos de pouco mais de dois kg por quilograma de $\mathrm{K}_{2} \mathrm{O}$ aplicado foi relativamente baixa nos quatro primeiros anos, concordando com as observações de Voll \& Bays (1976). Com a queda do efeito residual ecom odecréscimonatural das reservas do solo, a relação aumentou substancialmente nos demais anos, chegando a atingir, na soma das doze safras, um valor médio de $18 \mathrm{~kg}$ de grãos por $\mathrm{kg}$ de $\mathrm{K}_{2} \mathrm{O}$ adicionado. Esse valor é bastante relevante, indicando que o produtor poderá ter um bom retorno com adoção dessa tecnologia.

\section{Potássio no solo}

Nas curvas da figura 4a, observa-se a redução gradativa dos teores de $\mathrm{K}$ do solo no decorrer dos cultivos, fato que não chegou a comprometer a produtividade da soja nos quatro primeiros anos, mas com queda drástica nos anos seguintes (Figura 1). Outros trabalhos também têm mostrado quedas acentuadas no teor de K-disponível dos solos nos primeiros cultivos (Voll \& Bays, 1976; Mielniczuk \& Sel bach, 1978; Rosolem et al., 1984; Nachtigall \& Vahl, 1991), sem grandes respostas da cultura à adubação potássica (Voll \& Bays, 1976; Mascarenhas et al., 1981; Scherer et al., 1982).

Verifica-se, ainda, na figura $4 a$, que, nos primeiros anos, os teores de $\mathrm{K}$ do solo se mantiveram proporcionais às doses de adubo aplicadas. Com o passar do tempo eem conseqüência da maior extração pelas colheitas, os teores de $\mathrm{K}$ do solo nas parcelas com efeitos residuais de adubação do primeiro ano tenderam a senivelar. Aofinal de noveanos decultivo, os teores de $\mathrm{K}$ do solo de todas as parcelas com adubação potássica do primeiro ano tenderam a se estabilizar num patamar próximo a $30 \mathrm{mg} \mathrm{dm}^{-3}$, sem sofrer grandes alterações nos demais cultivos. Nachtigall \& Vahl (1991) encontraram efeito semel hante em um solo da região Sul do Rio Grande do Sul.

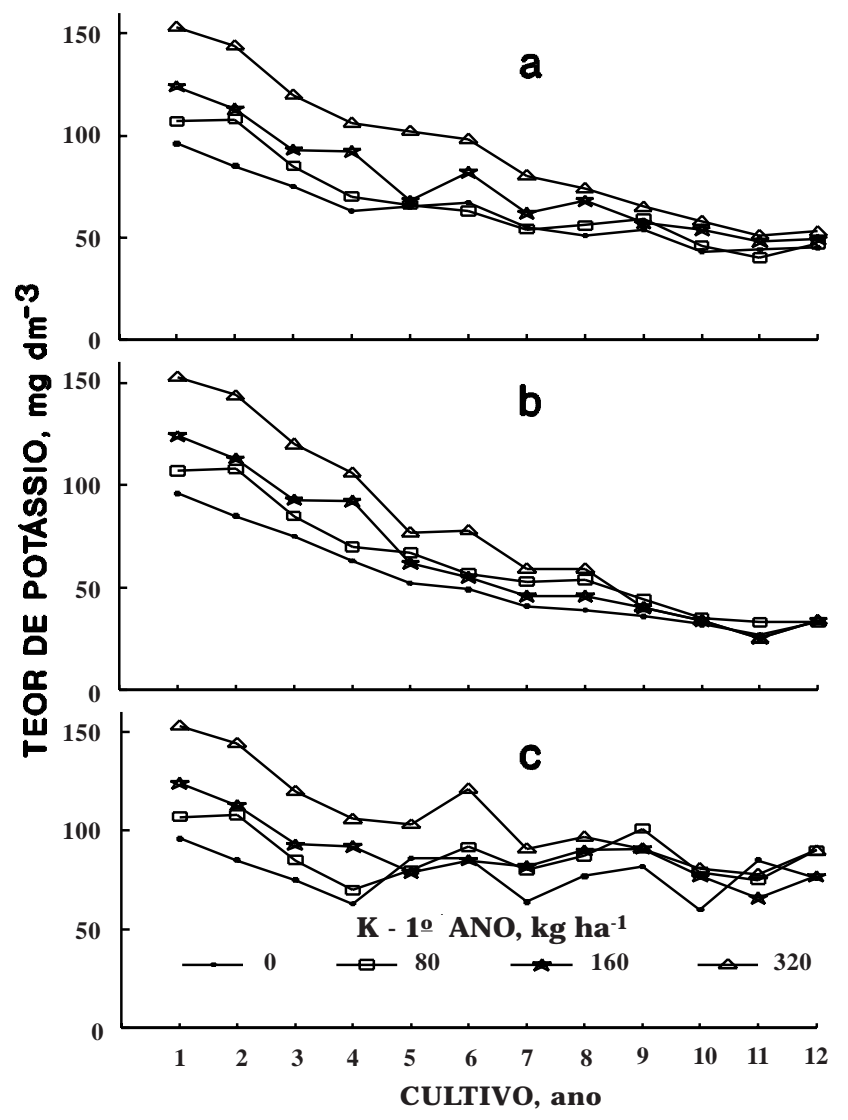

Figura 4. Teor de potássio disponível no solo em função das doses de adubo aplicadas, no primeiro ano, nas parcelas $\left(0,80,160\right.$ e $\left.320 \mathrm{~kg} \mathrm{ha}^{-1} \mathrm{de} \mathrm{K}_{2} \mathrm{O}\right)$, e, anualmente, (a: 0, b: 40 e c: $80 \mathrm{~kg} \mathrm{ha}^{-1}$ de $\mathrm{K}_{2} \mathrm{O}$ ), a partir do quinto ano, nas subparcelas. Média de três repetições.

Presume-se que, quando o $\mathrm{K}$ do solo atinge nível mínimo, ao redor de $30 \mathrm{mg} \mathrm{dm}^{-3}$, grande parte do suprimento do nutriente para as plantas depende da liberação de formas não-trocáveis, como evidenciaram Mascarenhas et al. (1981), Rosolem et al. (1988) e Nachtigall \& Vahl (1991). Nesse sentido, a presença ou não de plantas, otempo de repouso entre um cultivo e outro são fatores que também podem interferir na dinâmica do K no solo (Fernandes et al., 1993), alterando a resposta das plantas à adubação, como aconteceu quando o xinxo antecedeu a soja (Figura 1).

A aplicação anual de $40 \mathrm{~kg} \mathrm{ha}^{-1}$ de $\mathrm{K}_{2} \mathrm{O}$ não foi suficiente para manter constantes os teores de $\mathrm{K}$ do solo, acarretando decréscimos na disponibilidade ao longo dos anos de cultivo, em todos os níveis de Kresidual (Figura 4b). Essa diminuição caracteriza uma exaustão lenta do K nativo do solo ou daquele incorporado pela adubação, em função da retirada maior desse nutriente nas col heitas de grãos e na palha. De acordo com Fernandes et al. (1993), com o esgotamento do $\mathrm{K}$ nativo, o sol o depauperado requer doses muito maiores de $K$, suficientes não só para satisfazer à demanda da planta, mas também para repor as formas consideradas não-trocáveis, queforam utilizadas pela cultura. 
As curvas dos tratamentos com aplicação anual de $80 \mathrm{~kg} \mathrm{ha}^{-1} \mathrm{deK}_{2} \mathrm{O}$ (F igura 4c) mostraram uma clara redução do conteúdo de $\mathrm{K}$ do solo nos primeiros quatro anos, quandonão houvereaplicação deadubo potássico. Porém, com a reaplicação anual de $80 \mathrm{~kg}$ ha-1 de $_{2} \mathrm{O}$, a partir do quinto ano, os valores de $\mathrm{K}$ do solo aumentaram, atingindo novos patamares, que semantiveram mais ou menos constantes nos demais anos. Com a aplicação da maior dose (320 kg ha-1 de $\mathrm{K}_{2} \mathrm{O}$ ) no primeiro ano, seguida de $80 \mathrm{~kg} \mathrm{ha}^{-1}$ anuais de $\mathrm{K}_{2} \mathrm{O}$, a partir do quinto ano, manteve-se o teor de $\mathrm{K}$ do solo acima do nível crítico, porém num val or abaixo do teor inicial de $125 \mathrm{mg} \mathrm{dm}^{-3}$ deK, atingido somentenos dois primeiros anos de cultivo. Tais resultados são semel hantes aos obtidos por Rosolem et al. (1984) e Borkert et al. (1993), que mostraram a necessidade de aplicar maiores quantidades, acima de $80 \mathrm{~kg} \mathrm{ha}^{-1}$ de $\mathrm{K}_{2} \mathrm{O}$ por ano, para manter o nível de $\mathrm{K}$ do solo.

Considerando que parte do nutriente retirado do sol o poderia ser restituída, caso houvesse a reposição da pal ha nas unidades experimentais, uma aplicação anual de $60 \mathrm{~kg} \mathrm{ha}^{-1}$ de $\mathrm{K}_{2} \mathrm{O}$ (Figuras 1 e 2), seria suficiente para atender à demanda da cultura da soja e manter o teor no solo próximo a $80 \mathrm{mg} \mathrm{dm}^{-3}$, nível de suficiência considerado seguro para atingir altas produtividades. Essa adubação é inferior à recomendada pela Comissão de Fertilidade do Solo (1995) para uma sucessão de cultivos soja (65 kg ha-1 de $\mathrm{K}_{2} \mathrm{O}$ ) e trigo (60 kg ha-1 de $\mathrm{K}_{2} \mathrm{O}$ ), perfazendo um val or total dereposição de $125 \mathrm{~kg} \mathrm{ha}^{-1}$ de $_{2} \mathrm{O}$ nos anos com trigo.

\section{CONCLUSÕES}

1. O teor inicial de $125 \mathrm{mg} \mathrm{dm}^{-3}$ deK disponível no solo mostrou-se suficiente para atingir rendimentos máximos de soja nos quatro primei ros anos de cultivo, não havendo necessidade de adubar com $\mathrm{K}$.

2. A resposta da cultura à adubação potássica aumentou, à medida que os cultivos se sucediam, ea esse aumento correspondeu uma diminuição no teor de $\mathrm{K}$ do solo.

3. A aplicação anual de $60 \mathrm{~kg} \mathrm{ha}^{-1} \mathrm{~K}_{2} \mathrm{O}$ foi suficiente para atender à demanda da cultura da soja e manter o teor de K no solo próximo ao nível crítico.

4. O efeito residual da maior dose de $\mathrm{K}_{2} \mathrm{O}$ (320 kg ha-1), aplicada no primeiro cultivo, foi suficiente para manter a produtividade em níveis satisfatórios, durante seis cultivos de soja, eaumentar a produção de grãos, por mais seis anos, evidenciando o prolongado efeito residual da adubação potássica nesse tipo de solo.

5. Para cada $\mathrm{kg}$ de $\mathrm{K}_{2} \mathrm{O}$ aplicado no primeiro ano, obteve-se, ao final de doze cultivos, aumento médio de $18 \mathrm{~kg}$ de grãos de soja.

6. Não houve diferença em rendimento de grãos de soja entre o adubo potássico aplicado no sulco e a lanço, tampouco entre a adubação aplicada em dose única, toda no primeiro ano, e a parcelada, aplicada, anualmente, na semeadura da soja.

\section{LITE RATURA CITADA}

BEN, J.R. Resultados de pesquisa com potássio em soja no Rio Grande do Sul, Santa Catarina e Paraná. In: REUNIÃO DE PESQUISA DE SOJ A DA REGIÃO SUL, 9., Passo Fundo, 1981. Ata. Passo Fundo, EMBRAPA-CNPT, 1981. p.174.

BORKERT, C.M.; SFREDO, G.J . \& SILVA, D.N. Calibração de potássio trocável para soja em Latossolo Roxo distrófico. R. Bras. Ci. Solo, 17:223-226, 1993.

COMISSÃO DE FERTILIDADE DO SOLO - RS/SC Recomendações de adubação e de calagem para os estados do Rio Grande do Sul e de Santa Catarina. 3.ed. Passo Fundo, SBCS-Núcleo Regional Sul, 1995. 224p.

FERNANDES, D.M.; ROSSETO, C.A.V.; ISHIMURA, I. \& ROSOLEM, C.A. Nutrição da soja e formas de potássio no solo em função de cultivares e adubação potássica. R. Bras. Ci. Solo, 17:405-410, 1993.

MASCARENHAS, H.A.A.; NEPTUNE, A.M.L.; MURAOKA, T.; BULISANI, E.A. \& HIROCE, R. Absorção de nutrientes por cultivares de soja (Glicynemax (L.) Merrill). R. Bras. Ci. Solo, 4:92-96, 1980.

MASCARENHAS, H.A.A.; VALADARES, J.M.A.; ROTTA, C.L. \& BULISANI, E.A. Adubação potássica na produção de soja, nos teores de potássio nas fol has e na disponibilidade de potássio em Latossolo Roxo distrófico de cerrado. Bragantia, 40:125-134, 1981.

MASCARENHAS, H.A.A.; MIRANDA, M.A.C.; LÉLIS, L.G.L.; BULISANI, E.A.; BRAGA, N.R. \& PEREIRA, J.C.V.N.A. Haste verde e retenção foliar em soja por deficiência de potássio. Campinas, Instituto Agronômico, 1987. 15p. (Boletim Técnico, 119)

MASCARENHAS, H.A.A.; BULISANI, E.A.; MIRANDA, M.A.C.; PEREIRA, J.C.V.N.A. \& BRAGA, N.R. Deficiência de potássio em soja no Estado de São Paulo: melhor entendimento do problema e possíveis soluções. O Agronômico, 40:34-43, 1988.

MIELNICZUK, J. O potássio no solo. Piracicaba, Instituto da Potassa e do Fosfato/I nstituto I nternacional da Potassa, 1982. 80p. (Boletim Técnico, 2)

MIELNICZUK, J . \& SELBACH, P.A. Capacidade de suprimento de potássio de seis solos do Rio Grande do Sul. R. Bras. Ci. Solo, 2:115-120, 1978.

MUZI LLI , O. Nutrição e adubação potássica da soja no Brasil. In: SIMPÓSIO SOBRE POTÁSSIO NA AGRICULTURA BRASILEIRA, Londrina, 1982. Anais. Piracicaba, Instituto da Potasssa e do Fosfato/I nstituto Internacional da Potassa, 1982. p.339-372.

NACHTIGALL, G.R. \& VAHL, L.C. Dinâmica de liberação de potássio dos solos da região sul do Rio Grande do Sul. R. Bras. Ci. Solo, 15:43-47, 1991.

RAIJ , B. van. Fertilidade do solo e adubação. Piracicaba, Ceres/ Associação Brasileira para Pesquisa da Potassa e do Fosfato, 1991. 343p.

ROSOLEM, C.A.; NAKAGAVA, J . \& MACHADO, J.R. Adubação potássica da soja em $L$ atossolo Vermel ho-E scuro fase arenosa. Pesq. Agropec. Bras., 19:1319-1326, 1984. 
ROSOLEM, C.A.; MACHADO, J.R. \& RIBEIRO, D.B.O. Formas de potássio no solo e nutrição potássica da soja. R. Bras. Ci. Solo, 12:121-125, 1988.

SCHERER, E.E.; J UCKSCH, I. \& CASTILHOS, E.G. Avaliação da disponibilidade e do efeito residual do potássio no rendimento de grãos de soja. In: SOJ A - Resultados de Pesquisa obtidos em Santa Catarina no ano agrícola 1981/82. Chapecó, EMPASC-Estação Experimental de Chapecó, 1982. 15p.
SIQUEIRA, O.J.F. Nutrição e adubação potássica do trigo no Brasil. In: SIMPÓSIO SOBRE POTÁSSIO NA AGRICULTURA BRASILEIRA, Londrina, 1982. Anais. Piracicaba, Instituto da Potasssa e do Fosfato/I nstituto I nternacional da Potassa, 1982. p.449-486.

VOLL, E. \& BAYS, I .A. Correção e adubação do sol o para a cultura da soja em Latossolo Roxo distrófico. Pesq. Agropec. Bras., 11:93-99, 1976 